Г. В. Сокол ${ }^{1}$, А. О. Москаленко ${ }^{2}$, Н. В. Рвачова ${ }^{3}$, Т. В. Буряк ${ }^{1}$, Ю. В. Глуховець ${ }^{1}$, В. В. Варич ${ }^{1}$

${ }^{1}$ Полтавський національний технічний університет імені Юрія Кондратюка, Полтава, Укпаїна

${ }^{2}$ Полтавський інститут бізнесу ПВНЗ «Міжнародний науково-технічний університет імені академіка Юрія Бугая», Полтава, Укпаїна

${ }^{3}$ ТОВ НВП “Радікс”, Кропивницький, Укпаїна

\title{
ПЕРЕШКОДОСТІЙКІСТЬ СИГНАЛІВ МОДУЛЯЦІї ЦИКЛІЧНИМ ЗСУВОМ КОДУ З АДАПТАЦІЄЮ ПО ШВИДКОСТІ ПЕРЕДАЧІ ІНФОРМАЦЇ̈
}

\begin{abstract}
Предметом дослідження $є$ перешкодостійкість сигналів адаптивної модуляції. Мета - дослідження перешкодостійкості сигналів удосконаленої модуляції циклічним зсувом коду з адаптацією по швидкості передачі інформації. Результати досліджень. В роботі представлено результати порівняльного аналізу перспективних методів широкосмугової модуляції. Розглянуто основні принципи побудови перспективних радіоінтерфейсів. Запропоновані математичні моделі синтезу та кореляційної обробки сигналів модуляції циклічним зсувом коду з адаптацією по швидкості передачі інформації. Досліджено перешкодостійкість сигналів модуляції циклічним зсувом коду з адаптацією по швидкості передачі інформації. Висновки та область застосування результатів досліджень. Досліджено перешкодостійкість запропонованих сигналів. Використання сигналів модуляції циклічним зсувом коду з адаптацією по швидкості передачі інформації дозволить гнучко адаптувати параметри перспективних радіоінтерфейсів до умов поширення радіохвиль, зберігаючи максимальні швидкості передачі даних і мінімальну складність цифровий кореляційної обробки на прийомі.
\end{abstract}

Кл юч ов і слов а : модуляція циклічним зсувом коду, адаптивна модуляція, кореляційна обробка сигналів, швидке перетворення Фур'є, моделювання дискретного каналу зв'язку, математична модель.

\section{Вступ}

Постановка проблеми. На сьогодні, одним із пріоритетних завдань усіх силових структур України $є$ боротьба з тероризмом, загроза прояву якого використовується як засіб залякування держави у політичних цілях. Складність проведення заходів із протидії терористичним загрозам полягає у необхідності здійснення всього комплексу заходів, зокрема усунення чинників, що впливають на виникнення та розвиток тероризму (економічні, культурні і соціальні).

Ефективність проведення контртерористичних операцій напряму залежить від технічної оснащеності відповідних підрозділів, зокрема і комплексами радіозв'язку. Тому, виникає завдання у постійному вдосконаленні існуючих та розробці перспективних комплексів радіозв'язку.

При використанні вузькосмугових сигналів в системах бездротового зв'язку існує ряд недоліків: низька перешкодостійкість, низька структурна та енергетична скритність, неефективне використання частотного ресурсу та ін. Суттево покращити ці характеристики можливо шляхом використання сигналів з розширенням спектру.

Аналіз останніх досліджень і публікацій. Перспективними методами широкосмугової модуляції $€$ MBOK (M-ary Biorthogonal Keying - M-ічна двоортогональна модуляція), CCSK (Cyclic Code Shift Keying - модуляція циклічним зсувом коду), OCDM (Orthogonal Code Division Multiplex - мультиплексування сигналів з ортогональним кодовим ущільненням), OFDM (Orthogonal Frequency Division Multiplex - мультиплексування сигналів 3 ортогональним частотним ущільненням). За результатами аналізу даних методів модуляції встановлено, що найкращим методом $€$ MBOK завдяки високій стійкості до радіоперешкод та багатопроменевого розповсюдження радіохвиль $[1,2]$. Іншим перспективним методом є CCSK [3], він поступається М-ічній двоортогональній модуляції внаслідок використання неортогонального алфавіту сигналів та вразливості до багатопроменевого розповсюдження радіохвиль.

Змінюючи методи формування алфавіту сигналів CCSK-модуляції можливо усунути вказані недоліки $[4,5]$. В результаті чого, модуляція циклічним зсувом коду, у порівнянні з МВОК, отримує перевагу за рахунок забезпечення більш високої швидкості передачі інформації та простоти кореляційної обробки сигналів. Але, для задоволення вимог до високошвидкісної передачі даних перспективні радіоінтерфейси повинні використовувати частотний діапазон ефективніше, ніж відомі радіотехнології. А це передбачає можливість використання багаторівневих форматів модуляції з високою стійкістю до частотно-селективних завмирань, які спостерігаються в широкосмуговому радіоканалі. Тому, бажаною властивістю методів модуляції сигналів, які є кандидатами на використання в перспективних радіоінтерфейсах, $\epsilon$ можливість адаптації до умов розповсюдження радіохвиль.

В [6] запропонований метод синтезу сигналів удосконаленої модуляції циклічним зсувом коду 3 адаптацією за швидкістю передачі інформації, а також спосіб обробки сигналів, синтезованих з використанням запропонованого методу. Їх використання дозволяе гнучко адаптувати параметри перспективних радіоінтерфейсів до умов розповсюдження радіохвиль, зберігаючи максимальні швидкості передачі даних і мінімальну складність цифрової кореляційної обробки на прийомі. Проте, залишаються не дослідженими перешкодостійкість запропонованих сигналів в умовах багатопроменевого розповсюдження радіохвиль. 
Мета статті. Враховуючи це, метою статті $\epsilon$ дослідження перешкодостійкості сигналів модуляції циклічним зсувом коду з адаптацією по швидкості передачі інформації.

\section{Результати досліджень}

Метод модуляції циклічним зсувом коду 3 адаптацісю по швидкості передачі інформації. При формуванні сигналів модуляції циклічним зсувом коду з адаптацією по швидкості передачі інформації враховуються параметри середовища поширення радіохвиль в слідстві чого змінюється швидкість передачі інформаційних біт. Це відбувається шляхом оцінювання основних параметрів середовища поширення і видачі сигналів, що управляють, на зміни швидкості передачі інформації передавачу і приймачу [6].

При використанні запропонованого методу модуляції швидкість передачі інформації може знаходитися в межах:

$$
\frac{1}{\tau \cdot N} \leq V \leq \frac{\log _{2} N}{\tau \cdot N},
$$

де $\tau$ - протяжність чіпа; $N$ - довжина послідовності розширення спектра сигналів; $V$ - швидкість передачі інформації.

Приклад алгоритму формування сигналів модуляції циклічним зсувом коду 3 адаптацією по швидкості передачі інформації для кодової послідовності довжиною 8 біт приведений на рис. 1.

На рис.1 - ЗП (запам'ятовуючий пристрій). В запам'ятовуючому пристрої зберігається $N$ циклічних зсувів кодової послідовності розширення спектра сигналів довжиною $N$ біт.

Пристрій управління - здійснює управління швидкістю передавання інформації на основі отриманих даних. Для даного випадку, швидкість передачі інформації кратна ступеню двійки.

При формуванні сигналів на максимальній швидкості передавання інформації $\left(\frac{\log _{2} N}{\tau \cdot N}\right)$ кожна трійка інформаційних біт замінюється одним 3 восьми зсувів кодової послідовності розширення спектру сигналів, як і при класичній схемі CCSKмодуляції.

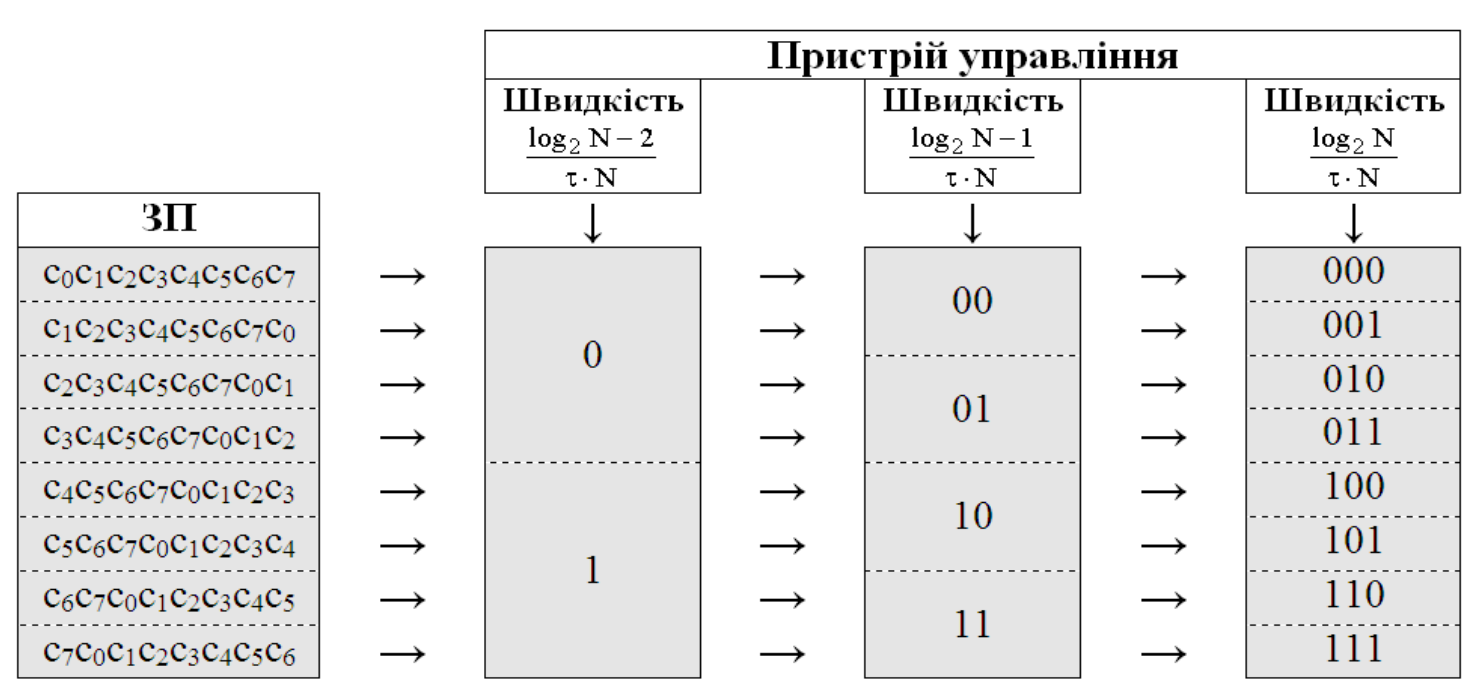

Рис. 1. Алгоритм формування сигналів модуляції циклічним зсувом коду з адаптацією по швидкості передачі інформації

Розглянемо приклад, коли надійшла команда на зміну швидкості передавання інформації до $\frac{\left(\log _{2} N-1\right)}{\tau \cdot N}$. В цьому випадку, сигнал формується таким чином. Кожна двійка інформаційних біт замінюється лише 1 (або 2), 3 (або 4), 5 (або 6) і 7 (або 8) циклічними зсувами відповідно до рис. 1. Сигнали при інших швидкостях передачі інформації формуються аналогічним чином.

Кореляційна обробка сигналів модуляції циклічним зсувом коду з адаптацісю по швидкості передачі інформації. Кореляційна обробка сигналів модуляції циклічним зсувом коду 3 адаптацією по швидкості передачі інформації передбачає обчислення швидкого перетворення Фур'є вхідного сигналу, його поелементне множення 3 комплексно-спряженим спектром опорного сигналу, і оберненого швидкого перетворення Фур'є отриманого результату, що практично аналогічно обробці сигналів з модуляцією циклічним зсувом коду (рис. 2). Різниця полягає в принципі роботи пристрою вирішення.

Принципи роботи пристрою вирішення при кореляційній обробці сигналів модуляції циклічним зсувом коду 3 адаптацією по швидкості передачі інформації представлено на рис. 3 .

Для прикладу розглянемо принципи роботи пристрою вирішення при кореляційній обробці сигналів модуляції циклічним зсувом коду з адаптацією по швидкості передачі інформації для довжини кодової послідовності 8 біт.

При максимальній швидкості передачі інформації $\left(\frac{\log _{2} N}{\tau \cdot N}\right)$ кореляційний обробка сигналів модуляції циклічним зсувом коду 3 адаптацією по швидкості передачі інформації аналогічна обробці сигналів 3 модуляцією циклічним зсувом коду. Кожній трійці інформаційних біт відповідає один стан кореляційної матриці. 


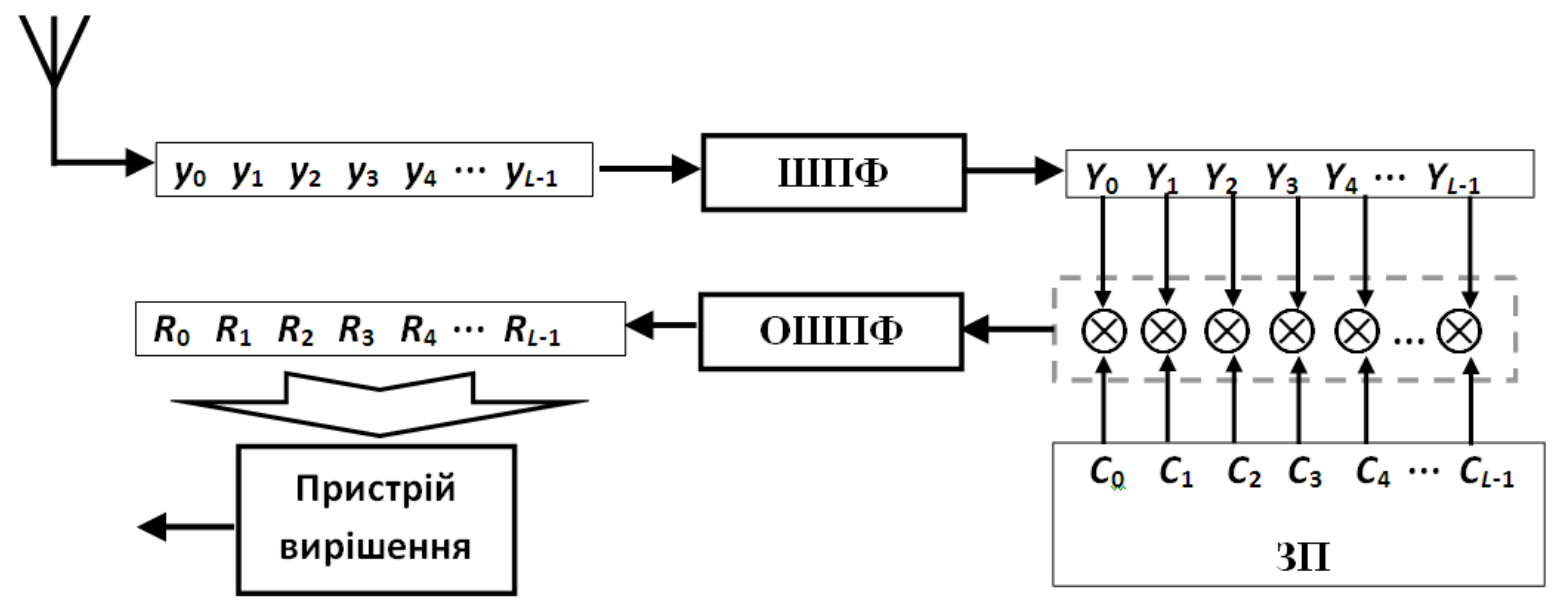

Рис. 2. Алгоритм кореляційної обробки сигналів модуляції циклічним зсувом коду з адаптацією по швидкості передачі інформації

\begin{tabular}{|c|}
\hline $\begin{array}{c}\text { Кореляційна } \\
\text { матриця }\end{array}$ \\
\hline 800000000 \\
\hline 08000000 \\
\hline 00800000 \\
\hline 00080000 \\
\hline 00008000 \\
\hline $\begin{array}{llllllll}0 & 0 & 0 & 0 & 0 & 8 & 0 & 0\end{array}$ \\
\hline 00000080 \\
\hline 00000008 \\
\hline
\end{tabular}

\begin{tabular}{|c|c|c|c|c|}
\hline \multicolumn{5}{|c|}{ Пристрій управління } \\
\hline $\begin{array}{c}\text { Швидкість } \\
\frac{\log _{2} \mathrm{~N}-2}{\tau \cdot \mathrm{N}}\end{array}$ & & $\begin{array}{c}\text { Швидкість } \\
\frac{\log _{2} \mathrm{~N}-1}{\tau \cdot \mathrm{N}}\end{array}$ & & $\begin{array}{c}\text { Швидкість } \\
\frac{\log _{2} \mathrm{~N}}{\tau \cdot \mathrm{N}} \\
\end{array}$ \\
\hline$\downarrow$ & & $\downarrow$ & & $\downarrow$ \\
\hline \multirow{4}{*}{0} & $\rightarrow$ & \multirow{2}{*}{00} & $\rightarrow$ & 000 \\
\hline & $\longrightarrow$ & & $\longrightarrow$ & 001 \\
\hline & $\rightarrow$ & \multirow{2}{*}{01} & $\rightarrow$ & 010 \\
\hline & $\rightarrow$ & & $\rightarrow$ & 011 \\
\hline \multirow{4}{*}{1} & $\rightarrow$ & \multirow{2}{*}{10} & $\longrightarrow$ & 100 \\
\hline & $\longrightarrow$ & & $\rightarrow$ & 101 \\
\hline & $\rightarrow$ & \multirow{2}{*}{11} & $\rightarrow$ & 110 \\
\hline & $\longrightarrow$ & & $\rightarrow$ & 111 \\
\hline
\end{tabular}

Рис. 3. Принципи роботи пристрою вирішення при кореляційній обробці сигналів модуляції циклічним зсувом коду з адаптацією по швидкості передачі інформації

При швидкості передачі інформації $\frac{\left(\log _{2} N-1\right)}{\tau \cdot N}$ кожній парі інформаційних біт відповідає два стани кореляційної матриці.

При швидкості передачі інформації $\frac{\left(\log _{2} N-2\right)}{\tau \cdot N}$ кожному інформаційному біту відповідає чотири стани кореляційної матриці.

Кореляційна обробка сигналів при інших швидкостях передачі інформації виконується аналогічним чином.

Перешкодостійкість сигналів модуляції циклічним зсувом коду з адаптацією по швидкості передачі інформації. За результатами моделювання, яке було проведено в середовищі Matlab, отримані залежності ймовірності помилкового прийому інформаційного біта $\left(\mathrm{P}_{\text {пом }}\right)$ від співвідношення часу затримки до часу проходження одного чіпа на вході приймача $\left(\tau_{3} / \tau_{\text {ч }}\right)$ при багатопроменевому розповсюдженні радіохвиль.

Залежності ймовірності помилкового прийому інформаційного біту від співвідношення часу затри- мки до часу проходження одного чіпа при використанні сигналів удосконаленої модуляції циклічним зсувом коду приведені на рис. 4 (а-в). Співвідношення амплітуд сигналів прямого і віддзеркаленого променю 1:1.

На рис. 4, а приведено залежність ймовірності помилкового прийому інформаційного біту від співвідношення часу затримки до часу проходження одного чіпа для швидкості передавання даних $\frac{\log _{2} N}{\tau \cdot N}$.

На рис. 4, 6 та 4, в приведено залежність ймовірності помилкового прийому інформаційного біту від співвідношення часу затримки до часу проходження одного чіпа для швидкостей передавання даних $\frac{\left(\log _{2} N-1\right)}{\tau \cdot N} \mathrm{i} \frac{\left(\log _{2} N-2\right)}{\tau \cdot N}$ відповідно.

За результатами моделювання з використанням сигналів удосконаленої модуляції циклічним зсувом коду, встановлено, що ймовірність помилкового прийому інформаційного біта наближається до 0,5 для максимальної швидкості передавання інформації 

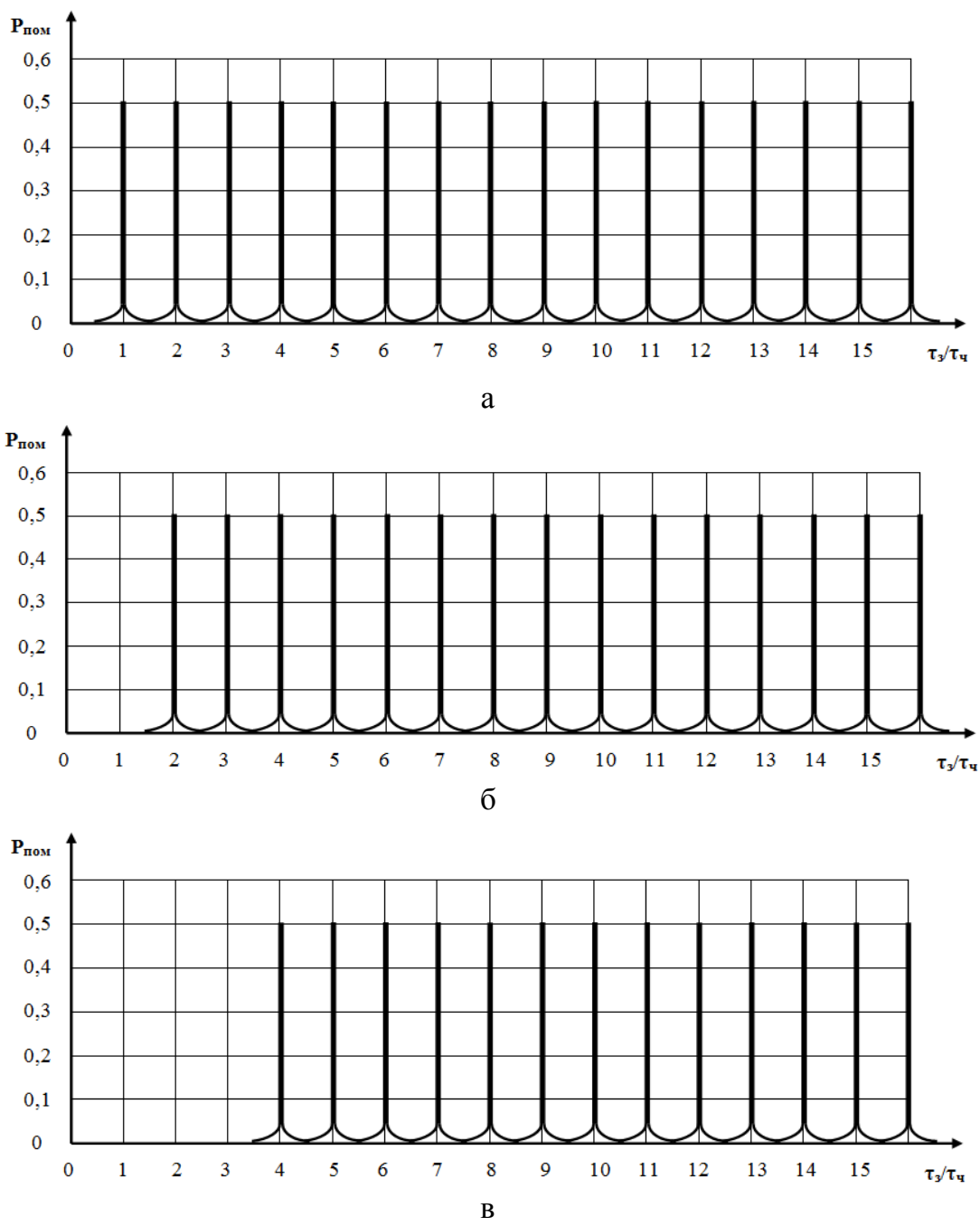

Рис. 4. Залежності ймовірності помилкового прийому інформаційного біту від співвідношення часу затримки до часу проходження одного чіпа при використанні сигналів модуляції циклічним зсувом коду з адаптацією по швидкості передачі інформації

у випадках, коли час затримки кратний тривалості чіпа, за умови що амплітуди віддзеркалених променів не більші за амплітуду прямого (рис. 4, a).

Для швидкості передавання інформації

$$
\frac{\left(\log _{2} N-1\right)}{\tau \cdot N}
$$

(рис. 4, б) ймовірність помилкового прийому інформаційного біта вперше наближається до 0,5 при затримці сигналу, кратній тривалості двох чіпів.

Далі характеристика аналогічна попередньому випадку.

Для швидкості передавання інформації

$$
\frac{\left(\log _{2} N-2\right)}{\tau \cdot N}
$$

(рис. 4, в) ймовірність помилкового прийому інформаційного біта вперше наближається до 0,5 при затримці сигналу, кратній тривалості чотирьох чіпів.

Далі характеристика аналогічна випадку, що ілюструє рис. 4 ,a.

Моделювання виконувалось для співвідношення амплітуд прямого і віддзеркаленого променів 1:1.

\section{Висновки}

Запропоновані математичні моделі синтезу та кореляційної обробки сигналів модуляції циклічним зсувом коду з адаптацією по швидкості передачі інформації, досліджено перешкодостійкість запропонованих сигналів.

Використання сигналів модуляції циклічним зсувом коду з адаптацією по швидкості передачі інформації дозволить гнучко адаптувати параметри перспективних радіоінтерфейсів до умов поширення радіохвиль, зберігаючи максимальні швидкості передачі даних і мінімальну складність цифровий кореляційної обробки на прийомі.

За результатами моделювання отримані залежності ймовірності помилкового прийому інформаційного біту від співвідношення часу затримки до часу проходження одного чіпа при використанні сигналів модуляції циклічним зсувом коду з адаптацією по швидкості передачі інформації.

Напрямком подальших досліджень $є$ отримання характеристик структурної та енергетичної скритності сигналів модуляції циклічним зсувом коду з адаптацією по швидкості передачі інформації. 
1. M. Webster et al., "Proposal for a high speed PHY for the 2.4 GHz band," IEEE P802.11-98/47, Jan. 1998.

2. Fisher et al., "DS-UWB physical layer submission to 802.15 task group 3a," IEEE P802.15-04/01373r3, July 2004.

3. G.M. Dillard et all., Cyclic Code Shift Keying: A Low Probability of Intercept Communication Technique // IEEE Trans. Aerosp. Electron. Systems., vol. AES-39, July 2003, pp. 786 -798.

4. Гепко И.А. Новый класс ортогональных кодов для телекоммуникационных систем CDMA и метод их корреляционного приема, минимизирующий вычислительную сложность цифрового сигнального процессора /И.А. Гепко, А.А.Москаленко// Зв’язок. - 2007. - № 6. - С. 33-39.

5. Гепко И.А. Свойства ортогональных сигналов с прямым расширением спектра на основе совершенных двоичных матриц и алгоритма их корреляционной обработки /И.А. Гепко, А.А.Москаленко// Радиоэлектроника (Изв. вузов). 2008. - № 1-2. - C. 49-60.

6. Москаленко А.А. Метод синтеза сигналов усовершенствованной модуляции циклическим сдвигом кода с адаптацией по скорости передачи информации / А.А.Москаленко, Г.В.Сокол// Науково-технічний журнал. Інформаційно керуючі системи на залізничному транспорті”, Харків, Випуск №3 (100), 2013. - С. 71-75.

\section{REFERENCES}

1. M. Webster et al., "Proposal for a high speed PHY for the $2.4 \mathrm{GHz}$ band," IEEE P802.11-98/47, Jan. 1998.

2. Fisher et al., "DS-UWB physical layer submission to 802.15 task group 3a," IEEE P802.15-04/01373r3, July 2004.

3. G.M. Dillard et all., Cyclic Code Shift Keying: A Low Probability of Intercept Communication Technique // IEEE Trans. Aerosp. Electron. Systems., vol. AES-39, July 2003, pp. 786-798.

4. Gepko I.A. Novyiy klass ortogonalnyih kodov dlya telekommunikatsionnyih sistem CDMA i metod ih korrelyatsionnogo priema, minimiziruyuschiy vyichislitelnuyu slozhnost tsifrovogo signalnogo protsessora /I.A. Gepko, A.A.Moskalenko// Zv'yazok. - 2007. - № 6. - S. 33-39.

5. Gepko I.A. Svoystva ortogonalnyih signalov s pryamyim rasshireniem spektra na osnove sovershennyih dvoichnyih matrits $i$ algoritma ih korrelyatsionnoy obrabotki /I.A. Gepko, A.A.Moskalenko// Radioelektronika (Izv. vuzov). - 2008. - № 1-2. - S. 4-60.

6. Moskalenko A.A. Metod sinteza signalov usovershenstvovannoy modulyatsii tsiklicheskim sdvigom koda s adaptatsiey po skorosti peredachi informatsii / A.A.Moskalenko, G.V.Sokol// Naukovo-tehnichniy zhurnal. Informatsiyno keruyuchi sistemi na zaliznichnomu transpori”, Harkiv, Vipusk №3 (100), 2013. - S. 71-75.

Рецензент: д-р техн. наук, проф. К. С. Козелкова, Державний університет телекомунікацій, Київ Received (Надійшла) 28.02.2018

Accepted for publication (Прийнята до друку) 25.04.2018

\section{Помехоустойчивость сигналов модуляции циклическим сдвигом кода с адаптацией по скорости передачи информации}

\section{Г. В. Сокол, А. А. Москаленко, Н. В. Рвачова, Т. В. Буряк., Ю. В. Глуховец, В. В. Варич}

Предметом исследования является помехоустойчивость сигналов адаптивной модуляции. Цель - исследование помехоустойчивости сигналов усовершенствованной модуляции циклическим сдвигом кода с адаптацией по скорости передачи информации. Результаты исследований. В работе представлены результаты сравнительного анализа перспективных методов широкополосной модуляции. Рассмотрены основные принципы построения перспективных радиоинтерфейсов. Предложены математические модели синтеза и корреляционной обработки сигналов модуляции циклическим сдвигом кода с адаптацией по скорости передачи информации, исследована помехоустойчивость сигналов модуляции циклическим сдвигом кода с адаптацией по скорости передачи информации. Выводы и область применения результатов исследований. Исследованы помехоустойчивость предложенных сигналов. Использование сигналов модуляции циклическим сдвигом кода с адаптацией по скорости передачи информации позволит гибко адаптировать параметры перспективных радиоинтерфейсов к условиям распространения радиоволн, сохраняя максимальные скорости передачи данных и минимальную сложность цифровой корреляционной обработки на приеме.

Ключевые слова: модуляция циклическим сдвигом кода, адаптивная модуляция, корреляционная обработка сигналов, быстрое преобразование Фурье, моделирование дискретного канала связи, математическая модель.

\section{The anti-jamming ability of modulation signals by register rotation with rate adaptation}

G. Sokol, A. Moskalenko, N. Rvachova, T. Buriak, Y. Hlukhovets, B. Varych

The research subject is the anti-jamming ability of adaptive modulations signals. The purpose of research is the investigation of improved modulation signals by register rotation with rate adaptation. Research results. The results of the comparative analysis of broadband modulations advanced techniques were considered in the paper. The main principles of perspective radio interfaces construction were considered. The mathematical models of synthesis and correlation processing of modulation signals by register rotation with rate adaptation were proposed. The anti-jamming ability of modulation signals by register rotation with rate adaptation was investigated. Conclusions and scope of research results. The anti-jamming ability of the proposed signals was analyzed. The using of modulation signals by register rotation with rate adaptation will provide flexible adaptation of perspective radio interfaces parameters to propagation radio-waves conditions, while the peak transfer rate and the minimal complexity of digital correlation processing on receiving are saved.

Keywords: modulation by register rotation, adaptive modulation, correlation signal processing, fast Fourier transform, discrete channel simulation, mathematical model. 